\title{
Prognostic Significance of High EphA1-4 Expression Levels in Locally Advanced Gastric Cancer
}

\author{
MIKITO INOKUCHI ${ }^{1}$, MASATOSHI NAKAGAWA ${ }^{1}$, NASRI BAOGOK ${ }^{1}$, YOKO TAKAGI ${ }^{2}$, \\ TOSHIRO TANIOKA ${ }^{1}$, KENTARO GOKITA ${ }^{1}$, KEISUKE OKUNO ${ }^{1}$ and KAZUYUKI KOJIMA ${ }^{3}$ \\ ${ }^{1}$ Department of Gastrointestinal Surgery, ${ }^{2}$ Department of Surgical Specialties, \\ ${ }^{3}$ Department of Minimally Invasive Surgery, Tokyo Medical and Dental University, Tokyo, Japan
}

\begin{abstract}
Background/Aim: Erythropoietin-producing hepatocellular carcinoma receptor A (EphA) is associated with angiogenesis and invasive tumor progression. In this study, we evaluated the EphAl-4 expression levels in advanced gastric cancer. Patients and Methods: Tumor tissues obtained from 114 patients with advanced gastric adenocarcinoma who underwent gastrectomy were analyzed. In addition, the impact of EPHA 1-4 mRNA expression on survival was analyzed using the Kaplan-Meier plotter database on the website. Results: High EphA 1, 2, and 4 expression levels were significantly related to recurrence $(p<0.01, p=0.04$, and $p<0.01)$. Both high EphA 1 and 4 expression levels were independent predictors of relapse-free interval (hazard ratio $[H R]=2.0, p=0.03 ; H R=2.4, p=0.03$ ) and disease-specific survival $(H R=2.0,95 \% \quad p=0.03$; $H R=2.5, p=0.02)$ on multivariate analysis. In the KaplanMeier plotter database, high EPHA2 mRNA expression was significantly associated with poor survival in patients with gastric cancer $(p=0.0098)$, and high expression levels of EPHAl and 4 tended to be associated with poor survival $(p=0.050, p=0.052)$. Conclusion: EphA 1, 2, and 4 may play key roles in recurrence and survival in patients with advanced gastric cancer.
\end{abstract}

Gastric cancer (GC) is a common cause of cancer-related death worldwide (1). Surgery followed by adjuvant chemotherapy is standard treatment for locally advanced GC. However, many patients with advanced disease have recurrence after complete macroscopic removal of the tumor

Correspondence to: Mikito Inokuchi, Department of Gastric Surgery, Tokyo Medical and Dental University, 1-5-45, Yushima, Bunkyo-ku, Tokyo 113-8519, Japan. Tel: +81 358035254, Fax: +81 338174126, e-mail: m-inokuchi.srg2@tmd.ac.jp

Key Words: Erythropoietin-producing hepatocellular carcinoma receptors, advanced gastric cancer. and metastatic lymph nodes. Many candidate prognostic factors or promising biomarkers have been proposed in gastric cancer, although few molecular targets are clinically valuable.

Erythropoietin-producing hepatocellular (Eph) receptors are the largest family of receptor tyrosine kinases and are activated by interacting with cell-surface ligands, ephrins. Eph receptors are classified into A-type (EphA 1-8 and EphA 10) and B-type (EphB1-4 and EphB6) according to their interactions with ephrin ligands (2). Eph receptors and ephrin ligands modify the organization of the actin cytoskeleton and influence the activities of integrins and intercellular adhesion molecules, thereby regulating cell morphology, adhesion, or migration (3). The up-regulation of Eph receptors and ephrin has been reported in various types of cancer. Eph and ephrin can promote tumor progression by activating downstream signaling pathways, while combinations of Eph receptors and ephrin ligands are thought to depend on the specific type of cancer (4).

We previously reported the immunohistochemical expression levels of individual EphA1, 2, 3, and 4 receptors in GC. Individual overexpression of EphA1, 2, 3, or 4 receptor was significantly associated with progression and survival in GC, although about half of the GCs in our previous studies were early stage (5-7). Therefore, the present study was designed to globally evaluate the clinical significance of EphA 1 to 4 receptor expression in locally advanced GC treated surgically with no residual tumor. In addition, we analyzed the effects of mRNA expression levels of EPHA1, 2, 3, and 4 on survival using a Kaplan-Meier plotter, which is an online analysis tool for investigating the effects of genes on survival in patients with GC (8).

\section{Patients and Methods}

Patients. The study group comprised a total of 114 patients who were given a histopathological diagnosis of advanced gastric adenocarcinoma and underwent gastrectomy without residual 
tumors from January 2003 through December 2007 in the Department of Gastrointestinal Surgery, Tokyo Medical and Dental University. No patient received neoadjuvant therapy. Each tumor was classified according to the TNM classification (9). All tumors were pathologically classified according to the World Health Organization (WHO) pathological classification. All patients were provided a sufficient explanation of the study and provided written informed consent. This study was approved by the Institutional Review Board of Tokyo Medical and Dental University (No. M2000-831). All patients were evaluated for recurrent disease by undergoing diagnostic imaging examinations (computed tomography, ultrasonography, magnetic resonance imaging, or endoscopy) every 3 to 6 months. Positron emission tomography and bone scintigraphy were additionally performed, if necessary. The median follow-up was 60 months (range=5-109 months). Twenty-one patients (18\%) received postoperative adjuvant chemotherapy with S-1 (an oral fluoropyrimidine preparation consisting of tegafur, gimeracil, and oteracil potassium; Taiho Co., Ltd., Tokyo, Japan) alone. A total of 48 (44\%) patients had recurrent disease. Finally, $46(40 \%)$ patients died of recurrent disease, and $3(3 \%)$ died of other causes. HER2 status was previously evaluated and scored according to standardized assessment criteria by one of the co-authors (YT).

Immunohistochemistry. The detailed method used to perform immunohistochemical analysis has been described in our previous reports (5-7). The antibody of EphA1 (mouse monoclonal antibody, MAB8303) was purchased from Abnova Inc. (Taipei, Taiwan), and antibodies of EphA2 (rabbit polyclonal antibody, sc-924), EphA3 (rabbit polyclonal antibody, sc-920), and EphA4 (rabbit polyclonal antibody, sc-921) were purchased from Santa Cruz Biotechnology, Inc. (Santa Cruz, CA, USA). Representative formalin-fixed, paraffin-embedded tissue blocks were sliced into 4 - $\mu$ m-thick sections. After deparaffinization and rehydration, antigen retrieval was performed. Subsequently, endogenous peroxidase and nonspecific binding were blocked. The slides were incubated with each antibody against EphA1 (dilution 1:500), EphA2 (dilution 1:100), EphA3 (dilution 1:500), and EphA4 (dilution 1:150) at $4^{\circ} \mathrm{C}$ overnight. The primary antibodies were purchased from Abcam (Cambridge, UK). The sections were incubated with peroxidaselabeled antirabbit or anti-mouse antibody (Histofine Simplestain Max PO; Nichirei Co., Tokyo, Japan) for $30 \mathrm{~min}$ at room temperature. Peroxidase activity was detected with diaminobenzidine (DAB; Nichirei Co., Tokyo, Japan). Subsequently, the sections were counterstained with Mayer's hematoxylin (Wako, Tokyo, Japan). Negative control sections were treated similarly, except that the antibodies were replaced by normal rabbit IgG (Santa Cruz Biotechnology, Inc.). Strongly stained gastric specimens obtained from the same block were used as positive controls to reduce bias arising from the staining conditions in each immunohistochemical assay.

Interpretation of immunohistochemical staining. The stained slides were evaluated by at least two separate investigators (YT, MN, and NB) who were blinded to the patients' outcomes. The investigators counted wholly stained cancer cells of representative cross-sectional slices. To evaluate heterogeneous staining of cancer cells, we counted at least three fields per section of the invasive front of each tumor. The scoring system of EphA staining was somewhat modified in this study, because different scoring systems were used in previous studies (5-7). The staining intensity was scored into the following three grades: 0 , no staining; 1 , weakly positive; and 2, moderately or strongly positive. The staining extent (positive frequency) was also scored into three grades according to the percentage of stained tumor cells as follows: $0,<10 \% ; 1,10 \%$ to $50 \%$; and 2, $>50 \%$ stained cells. For statistical analysis, composite scores were calculated by adding the intensity and extent scores. Composite scores of $\geq 3$ were defined as high expression, and scores of $<3$ were defined as low expression.

Statistical analysis. Categorical data were compared with the use of the chi-square test or Fisher's exact test, as appropriate. KaplanMeier curves were plotted to assess the effect of EphA expression levels on relapse-free interval (RFI) and disease-free survival (DSS), and different survival curves were compared using the logrank test. Before multivariable analysis it was confirmed that the prognostic factors did not strongly correlate with each other. Multivariable Cox proportional hazards regression models were used to assess the prognostic significance of EphA expression levels and of several clinicopathological factors associated with RFI and DSS. Values of $p<0.05$ were considered to indicate statistical significance. All statistical analyses were performed with the statistical software package SPSS 24 (SPSS Japan Inc., Tokyo, Japan).

Survival analysis using the Kaplan-Meier plotter database. The Kaplan-Meier plotter datasets were obtained from Gene Expression Omnibus, Cancer Biomedical Informatics Grid, and The Cancer Genome Atlas. In the present study, the Kaplan-Meier plotter database http://kmplot.com/analysis/index.php? $p=$ service $\&$ cancer $=$ gastric, accessed November 17th, 2017) was used to show the distinct prognostic values of the EPHA 1,2, 3, and 4 genes in GC. We excluded the GSE52254 dataset from the present study because of markedly different characteristics as compared with the other datasets of GC in compliance with the website suggestion and then included the remaining five datasets in this study (GSE14210, GSE15459, GSE22377, GSE29272, GSE51105) (8). The JetSet best probe sets were selected for each gene (EPHA1, 205977_s_at; EPHA2, 203499_at; EPHA3, 206070_s_at; EPHA4, 227449_at) in compliance with the website recommendation. The cut-off values of high or low mRNA expression were also selected automatically on the website. Thus, the overall survival curves associated with high or low expression of EPHAI - 4 mRNA levels were available on the website. The survival curves were compared using the logrank test.

\section{Results}

High EphA1, 2, 3, and 4 expressions were observed in 63 $(55 \%), 83(72 \%), 63(55 \%)$, and $69(61 \%)$ tumors, respectively (Figure 1). The relations between EphA expressions and clinicopathological factors are shown in Table I. High EphA1 and EphA3 expression levels were significantly associated with undifferentiated type $(p<0.01)$ and differentiated type $(p<0.01)$, respectively. Serosal invasion was significantly associated with high EphA4 expression $(p<0.01)$. No expression level was related to lymphatic invasion by the primary tumor, whereas only high EphA2 expression was significantly related to venous 

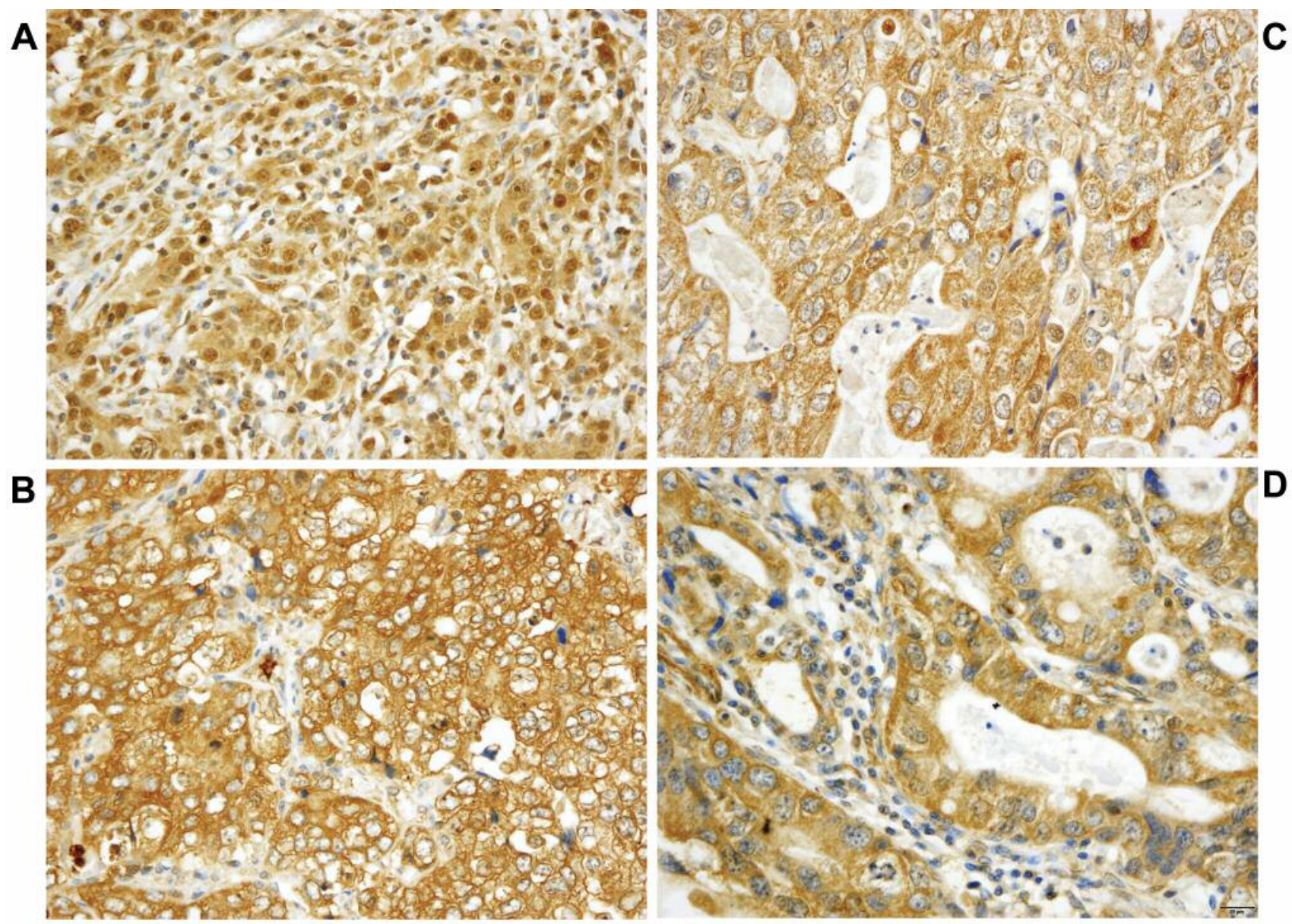

Figure 1. Immunostaining for EPHAs in representative primary gastric cancers, EPHA1 (A), EPHA2 (B), EPHA3 (C), and EPHA4 (D). Magnification X400.

invasion by the primary tumor $(p=0.01)$. Lymphatic metastasis was significantly associated with high EphA2 and 4 expression levels $(p=0.02, p<0.01)$. Advanced stage (stage III $v s$. I/II) was significantly associated with high EphA3 and 4 expression levels $(p=0.03, p<0.01)$.

Recurrence was significantly more frequent in patients with high EphA1, 2, and 4 expression levels than in patients with low EphA1, 2, and 4 expression levels $(p<0.01, p=0.04$, and $p<0.01)$. In particular, lymphatic recurrence was significantly associated with high EphA1 and 4 expression levels $(p=0.03, p=0.01)$, and peritoneal recurrence was slightly but not significantly associated with high EphA1 and 4 expression levels $(p=0.08, p=0.07)$. Hematogenous recurrence was not significantly associated with any expression level. The presence of only high EphA3 expression was not associated with recurrence, but was significantly associated with male sex $(p=0.03)$, higher age $(>65$ years $)(p=0.03)$, and high HER2 expression $(p=0.02)$.
Patients with high EphA1, 2, and 4 expression levels had significantly shorter RFIs than patients with low expression levels ( $p=0.02, p=0.04$, and $p<0.01$; Figure 2). High EphA1 and 4 expression levels were both independent predictors of RFI on multivariate analysis of clinicopathological features adjusted for the following variables: serosal invasion, lymphnode metastasis, pathological type, and high EphA expression levels (EphA1, hazard ratio $[\mathrm{HR}]=2.0,95 \%$ confidence interval $(\mathrm{CI})=1.1-3.9, p=0.03$; EphA4, HR=2.4, 95\%CI $=1.1$ 5.3, $p=0.03$; Table II). As for RFI, high EphA1 and 4 expression levels were both independent prognostic factors of DSS on multivariate analysis $(\mathrm{HR}=2.0,95 \% \mathrm{CI}=1.1-3.9$, $p=0.03$; HR=2.5, 95\% CI $=1.1-5.5, p=0.02$; Table III). As for combinations of EphA expression, the subgroup of patients with 3 or more high expression levels of EphA1-4 had the worst RFI as compared with the subgroup of patients with no high expression and the subgroup of patients with only 1 or 2 high expression levels. RFI differed significantly among the 3 groups ( $p=0.001$, Figure 3 ). 
Table I. Relations between the expression levels of EphA1 to 4 and clinicopathological factors.

\begin{tabular}{|c|c|c|c|c|c|c|c|c|c|c|c|c|c|}
\hline \multirow[t]{2}{*}{ Clinicopathological factors } & \multirow[b]{2}{*}{$\mathrm{n}$} & \multicolumn{2}{|c|}{ EPHA1 } & \multirow[b]{2}{*}{$p$-Value } & \multicolumn{2}{|c|}{ EPHA2 } & \multirow[b]{2}{*}{$p$-Value } & \multicolumn{2}{|c|}{ EPHA3 } & \multirow[b]{2}{*}{$p$-Value } & \multicolumn{2}{|c|}{ EPHA4 } & \multirow[b]{2}{*}{$p$-Value } \\
\hline & & $\begin{array}{l}\text { High } \\
(\mathrm{n}=63)\end{array}$ & $\begin{array}{l}\text { Low } \\
(\mathrm{n}=51)\end{array}$ & & $\begin{array}{c}\text { High } \\
(\mathrm{n}=83)\end{array}$ & $\begin{array}{l}\text { Low } \\
(\mathrm{n}=31)\end{array}$ & & $\begin{array}{l}\text { High } \\
(\mathrm{n}=63)\end{array}$ & $\begin{array}{l}\text { Low } \\
(\mathrm{n}=51)\end{array}$ & & $\begin{array}{c}\text { High } \\
(\mathrm{n}=69)\end{array}$ & $\begin{array}{l}\text { Low } \\
(\mathrm{n}=45)\end{array}$ & \\
\hline \multicolumn{14}{|l|}{ Age (years) } \\
\hline$>65$ & 62 & 35 & 27 & \multirow[t]{2}{*}{0.78} & 44 & 18 & \multirow[t]{2}{*}{0.63} & 40 & 22 & \multirow[t]{2}{*}{0.03} & 39 & 23 & \multirow[t]{2}{*}{0.57} \\
\hline$<65$ & 52 & 28 & 24 & & 39 & 13 & & 23 & 29 & & 30 & 22 & \\
\hline \multicolumn{14}{|l|}{ Gender } \\
\hline Female & 25 & 13 & 12 & \multirow[t]{2}{*}{0.71} & 18 & 7 & \multirow[t]{2}{*}{0.92} & 9 & 16 & \multirow[t]{2}{*}{0.03} & 12 & 13 & \multirow[t]{2}{*}{0.15} \\
\hline Male & 89 & 50 & 39 & & 65 & 24 & & 54 & 35 & & 57 & 32 & \\
\hline Tumor location & & & & & & & & & & & & & \\
\hline $\mathrm{U}$ & 32 & 20 & 12 & 0.33 & 24 & 8 & 0.74 & 20 & 12 & 0.33 & 18 & 14 & 0.56 \\
\hline $\mathrm{M} / \mathrm{L}$ & 82 & 43 & 39 & & 59 & 23 & & 43 & 39 & & 51 & 31 & \\
\hline Pathological type & & & & & & & & & & & & & \\
\hline Undiff & 65 & 44 & 21 & $<0.01$ & 46 & 19 & 0.57 & 25 & 40 & $<0.01$ & 36 & 29 & 0.20 \\
\hline Diff & 44 & 19 & 30 & & 37 & 12 & & 38 & 11 & & 33 & 16 & \\
\hline Serosal invasion & & & & & & & & & & & & & \\
\hline Positive & 48 & 27 & 21 & 0.86 & 39 & 9 & 0.08 & 29 & 19 & 0.35 & 36 & 12 & $<0.01$ \\
\hline Negative & 66 & 36 & 30 & & 44 & 22 & & 34 & 32 & & 33 & 33 & \\
\hline Venous invasion & & & & & & & & & & & & & \\
\hline Positive & 94 & 53 & 41 & 0.60 & 73 & 21 & 0.01 & 55 & 39 & 0.13 & 60 & 34 & 0.12 \\
\hline Negative & 20 & 10 & 10 & & 10 & 10 & & 8 & 12 & & 9 & 11 & \\
\hline Lymphatic invasion & & & & & & & & & & & & & \\
\hline Positive & 96 & 54 & 42 & 0.63 & 69 & 27 & 0.78 & 53 & 43 & 0.98 & 58 & 38 & 0.96 \\
\hline Negative & 18 & 9 & 9 & & 14 & 4 & & 10 & 8 & & 11 & 7 & \\
\hline Lymph-node metastasis & & & & & & & & & & & & & \\
\hline Positive & 74 & 43 & 31 & 0.41 & 59 & 15 & 0.02 & 45 & 29 & 0.11 & 52 & 22 & $<0.01$ \\
\hline Negative & 40 & 20 & 20 & & 24 & 16 & & 18 & 22 & & 17 & 23 & \\
\hline Tumor stage & & & & & & & & & & & & & \\
\hline III & 60 & 34 & 26 & 0.75 & 48 & 12 & 0.07 & 39 & 21 & 0.03 & 44 & 16 & $<0.01$ \\
\hline $\mathrm{IB} / \mathrm{II}$ & 54 & 29 & 25 & & 35 & 19 & & 24 & 30 & & 25 & 29 & \\
\hline Recurrence & & & & & & & & & & & & & \\
\hline Positive & 47 & 33 & 14 & $<0.01$ & 39 & 8 & 0.04 & 28 & 19 & 0.44 & 38 & 9 & $<0.01$ \\
\hline Negative & 67 & 30 & 37 & & 44 & 23 & & 35 & 32 & & 31 & 36 & \\
\hline Peritoneal recurrence & & & & & & & & & & & & & \\
\hline Positive & 19 & 14 & 5 & 0.08 & 15 & 4 & 0.51 & 11 & 8 & 0.21 & 15 & 4 & 0.07 \\
\hline Negative & 95 & 49 & 46 & & 68 & 27 & & 55 & 40 & & 54 & 41 & \\
\hline Hematogenous recurrenc & & & & & & & & & & & & & \\
\hline Positive & 15 & 8 & 7 & 0.87 & 13 & 2 & 0.35 & 11 & 4 & 0.13 & 11 & 4 & 0.28 \\
\hline Negative & 99 & 55 & 44 & & 70 & 29 & & 52 & 47 & & 58 & 41 & \\
\hline Lymphatic recurrence & & & & & & & & & & & & & \\
\hline Positive & 21 & 16 & 5 & 0.03 & 18 & 3 & 0.14 & 14 & 7 & 0.25 & 18 & 3 & 0.01 \\
\hline Negative & 93 & 47 & 46 & & 65 & 28 & & 49 & 44 & & 51 & 42 & \\
\hline HER2 score & & & & & & & & & & & & & \\
\hline $2 / 3$ & 13 & 5 & 8 & 0.20 & 8 & 5 & 0.34 & 11 & 2 & 0.02 & 7 & 6 & 0.60 \\
\hline $0 / 1$ & 101 & 58 & 43 & & 75 & 26 & & 52 & 49 & & 62 & 39 & \\
\hline
\end{tabular}

In the analysis of overall survival using the Kaplan-Meier plotter database, EPHA1, 2, and 3 expression levels were analyzed in 593 patients, and EPHA4 expression levels were analyzed in 348 patients. High mRNA levels of the EPHAl, 2 , and 3 genes were present in 444 patients (75\%), 427 patients $(72 \%)$, and 395 patients $(67 \%)$, respectively. High EPHA4 expression was found in 116 patients (33\%). The survival curves are shown in Figure 4. High EPHA2 expression was significantly associated with poor survival $(p=0.0098)$. High EPHAl and 4 expression levels were associated with slightly but not significantly poorer survival ( $p=0.050, p=0.052$, respectively). Conversely, high EPHA3 expression was significantly associated with better survival $(p=0.0013)$. 

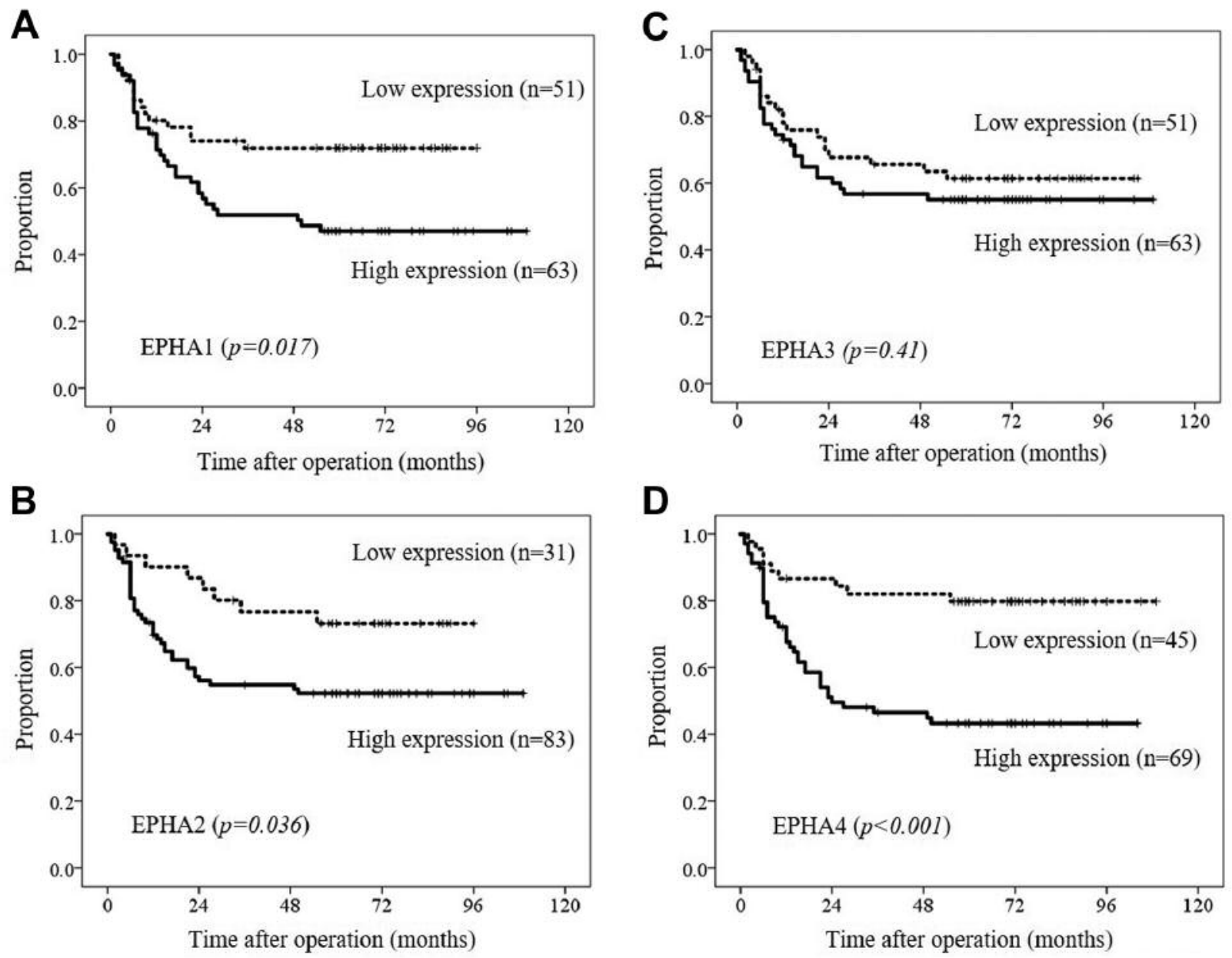

Figure 2. Survival curves of our samples. The Kaplan-Meier curve for the relapse-free interval of patients with EphA1 (A), EphA2 (B), EphA3 (C), and EphA4 protein expression (D).

\section{Discussion}

Our results showed that high EphA1 and 4 protein expression levels were independent predictors of RFI in patients with locally advanced GC and were significantly associated with recurrent disease, especially lymph-node recurrence. EphA4 expression was also significantly related to serosa invasion and lymph-node metastasis in the present study, whereas EphA1 was significantly related to these variables only in undifferentiated-type GC.

Several studies have previously assessed EphA4 expression in human gastrointestinal cancers. In another study of GC, EphA4 overexpression was significantly related to tumor growth factors and recurrence (10). EphA4 was significantly associated with the invasion depth of the primary tumor, lymph-node metastasis, and survival in patients with rectal cancer. More interestingly, high EphA4 expression was a significant predictor of a poor response to

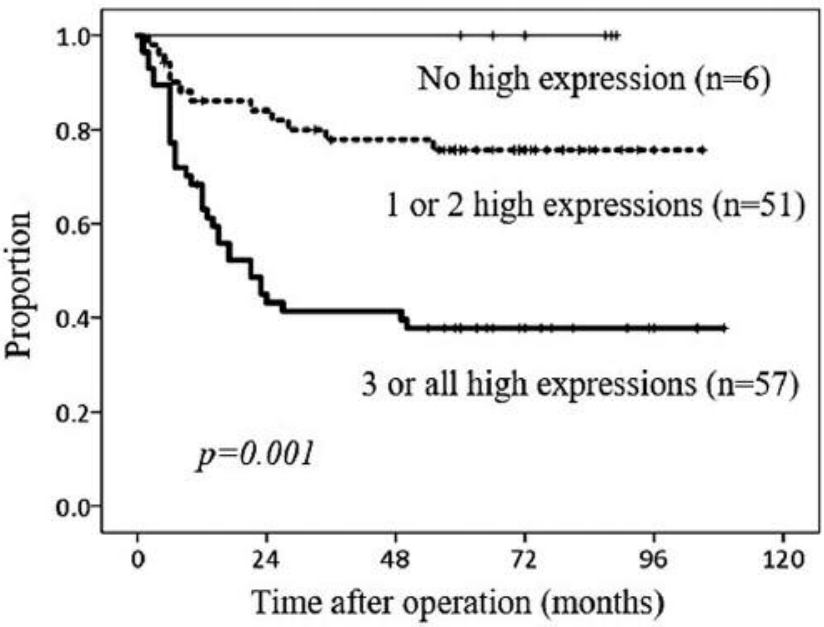

Figure 3. Survival curve based on the number of EphA with high expression levels. 
Table II. Prognostic factors for relapse-free interval in univariate and multivariate Cox proportional-hazards regression models.

\begin{tabular}{|c|c|c|c|c|}
\hline \multirow[t]{2}{*}{ Prognostic factors } & \multicolumn{2}{|c|}{ Univariate (log-rank) } & \multicolumn{2}{|l|}{ Multivariate } \\
\hline & $\begin{array}{c}\text { 5-year } \\
\text { RFI (\%) }\end{array}$ & $p$-Value & $\mathrm{HR} \quad 95 \% \mathrm{CI}$ & $p$-Value \\
\hline
\end{tabular}

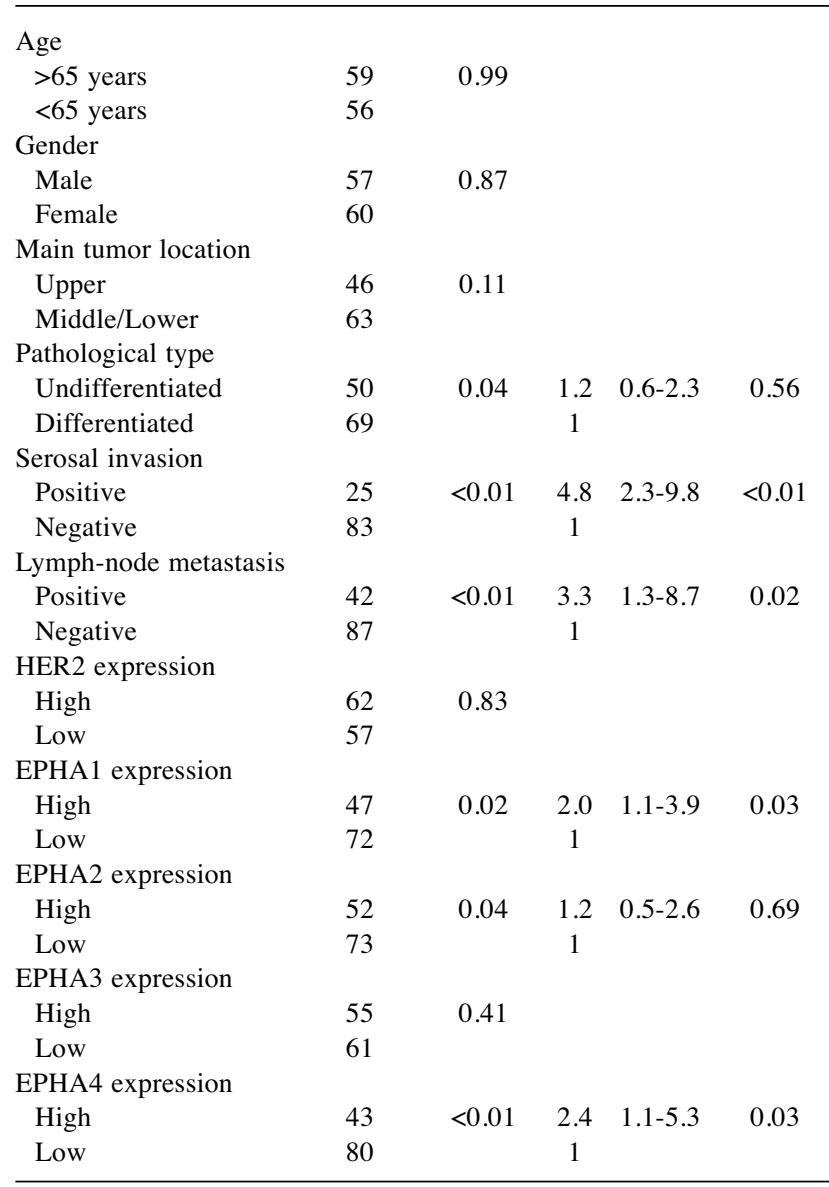

RFI: Relapse-free interval; HR: hazard ratio; CI: confidence interval.

chemoradiotherapy in rectal cancer (11). Another study showed that tumors with higher EPHA4 mRNA levels were significantly associated with liver metastasis from colorectal cancer (12), whereas our study did not show a positive relationship between EphA4 protein expression and hematogenous recurrence in GC. This discrepancy might be ascribed to methodological differences or different recurrence patterns between GC and colorectal cancer. Recurrence of GC is mainly associated with lymphatic, peritoneal, and hematogenous metastasis, while recurrence of colorectal cancer is mainly associated with hematological metastasis and local recurrence.

In another study of EphA1 in GC, high EphA1 protein expression was associated with advanced disease, lymph-
Table III. Prognostic factors for disease-specific survival in univariate and multivariate Cox proportional-hazards regression models.

\begin{tabular}{|c|c|c|c|c|c|}
\hline \multirow[t]{2}{*}{ Prognostic factors } & \multicolumn{2}{|c|}{ Univariate (log-rank) } & \multicolumn{3}{|c|}{ Multivariate } \\
\hline & $\begin{array}{c}5 \text {-year } \\
\text { DSS (\%) }\end{array}$ & $p$-Value & HR & $95 \% \mathrm{CI}$ & $p$-Value \\
\hline \multicolumn{6}{|l|}{ Age } \\
\hline$>65$ years & 64 & 0.72 & & & \\
\hline$<65$ years & 63 & & & & \\
\hline \multicolumn{6}{|l|}{ Gender } \\
\hline Male & 62 & 0.66 & & & \\
\hline Female & 68 & & & & \\
\hline \multicolumn{6}{|l|}{ Main tumor location } \\
\hline Upper & 52 & 0.16 & & & \\
\hline Middle/Lower & 68 & & & & \\
\hline \multicolumn{6}{|l|}{ Pathological type } \\
\hline Undifferentiated & 56 & 0.11 & & & \\
\hline Differentiated & 73 & & & & \\
\hline \multicolumn{6}{|l|}{ Serosal invasion } \\
\hline Positive & 33 & $<0.01$ & 5.0 & $2.5-10.0$ & $<0.01$ \\
\hline Negative & 86 & & 1 & & \\
\hline \multicolumn{6}{|c|}{ Lymph-node metastasis } \\
\hline Positive & 49 & $<0.01$ & 3.3 & $1.3-8.8$ & 0.01 \\
\hline Negative & 90 & & 1 & & \\
\hline \multicolumn{6}{|l|}{ HER2 expression } \\
\hline High & 62 & 0.97 & & & \\
\hline Low & 64 & & & & \\
\hline \multicolumn{6}{|l|}{ EPHA1 expression } \\
\hline High & 53 & 0.02 & 2.0 & $1.1-3.9$ & 0.03 \\
\hline Low & 76 & & 1 & & \\
\hline \multicolumn{6}{|l|}{ EPHA2 expression } \\
\hline High & 57 & 0.02 & 1.3 & $0.6-3.0$ & 0.69 \\
\hline Low & 76 & & 1 & & \\
\hline \multicolumn{6}{|l|}{ EPHA3 expression } \\
\hline High & 61 & 0.52 & & & \\
\hline Low & 66 & & & & \\
\hline \multicolumn{6}{|l|}{ EPHA4 expression } \\
\hline High & 51 & $<0.01$ & 2.5 & $1.1-5.5$ & 0.02 \\
\hline Low & 82 & & 1 & & \\
\hline
\end{tabular}

DSS: Disease-specific survival; HR: hazard ratio; CI: confidence interval.

node metastasis, and poorer survival of patients, although EphA protein expression was down-regulated in most tumors with methylation of the EPHAl gene (13). We previously showed that no tumor with high EphA1 protein expression has the gene amplification on fluorescence in situ hybridization (6). Several in vitro studies have demonstrated the tumor-progressive function of EphA1. Knockdown of the EPHAl gene inhibited proliferation, invasion, and migration via the regulation of multiple signaling pathways, such as matrix metalloproteinase (MMP)-2, extracellular signal-regulated kinase 2 (ERK2), and proto-oncogene c-MYC in ovarian cancer cell-lines (14). EphA1-activated SDF-1 expression enhanced the recruitment of endothelial progenitor cells, which can 

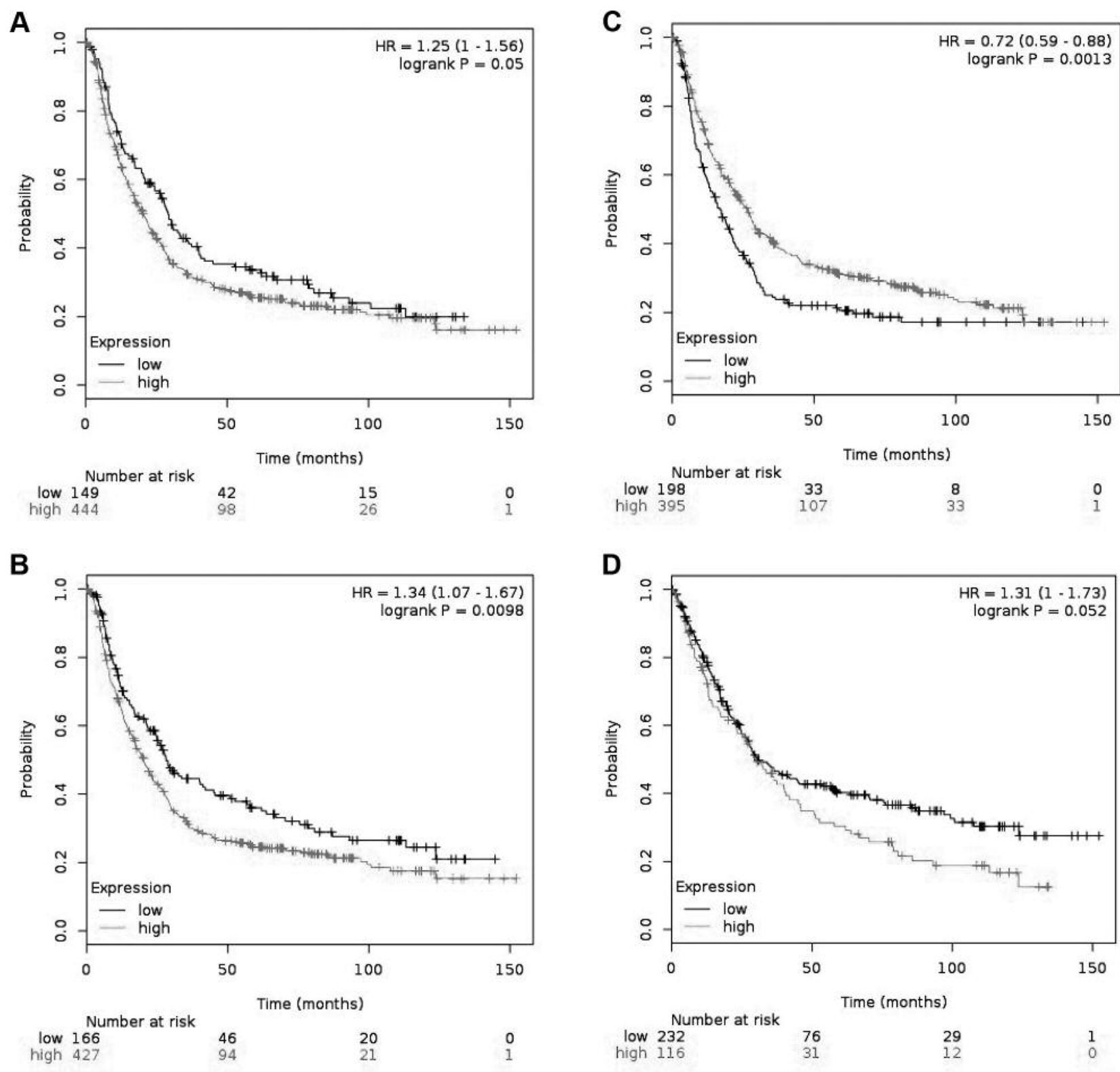

Figure 4. Survival curves in the Kaplan-Meier plotter database. The Kaplan-Meier curve for the overall survival of patients with EPHA1 (A), EPHA2 (B), EPHA3 (C), and EPHA4 gene expression $(D)$.

promote angiogenesis, to hepatocellular cancer cells (15). On the other hand, EphA1 expression is down-regulated in advanced colorectal cancer (16).

EphA2 is up-regulated in many cancers and its expression has been linked to increased malignancy and poor clinical outcomes (4). Some functions of EphA2 have been reported in various malignancies. EphA2 signaling in malignant melanoma can promote vascular mimicry (17). The consequent activation of EphA2 by ephrin-A1 enhances the angiogenic effects of VEGF in endothelial cells (18). In colorectal cancer, EphA2 overexpression was associated with high density of microvessels (19). EphA2 activated Akt in glioma stem cells (20). Conversely, however, EphA2 has been reported to have tumor suppressive activity in non-small cell lung carcinoma (21). Activated Akt decreases EphA2 phosphorylation through a negative regulatory loop and can thus inhibit cell migration and invasion (22).

EphA3 was highly expressed in various cancers (23). In another study of GC including early disease, high EphA3 protein expression was significantly associated with tumor 
depth, lymph-node metastasis, distant metastasis, poor survival of patients, and VEGF expression (24). EphA3 was related to both differentiated-type and HER2 expression and tended to be associated with hematogenous recurrence in the present study. EphA3 overexpression was related to poor outcomes in patients with hepatocellular carcinoma and colorectal cancer $(25,26)$.

We could not analyze the gene expression levels of EPHA 1 and 4 in our GC samples. We therefore used the Kaplan-Meier plotter database to analyze the impact of these levels on survival. Overexpression of EPHA 1, 2, and 4 was associated with poor survival in GC, as protein overexpression was associated with recurrence and poor survival in our immunohistochemical study. EPHA3 overexpression was conversely associated with outcomes, while the protein expression was not associated with recurrence in our immunohistochemical study. Nearly all GC tumors in the database were advanced, although a detailed TNM classification was unavailable because of blank data.

In conclusion, immunohistochemical high expression levels of EphA1, 2, and 4 may play key roles in recurrence and outcomes of advanced GC. In particular, EphA1 or 4 was an independent predictor of survival in advanced GC treated by surgery. The inhibition of EphA1, 2, and 4 might serve as a target for preventing tumor metastasis in GC.

\section{Conflicts of Interest}

The Authors have no conflicts of interest or financial ties to disclosure.

\section{References}

1 Torre LA, Bray F, Siegel RL, Ferlay J, Lortet-Tieulent J and Jemal A: Global cancer statistics, 2012. CA Cancer J Clin 65: 87-108, 2015.

2 Surawska H, Ma PC and Salgia R: The role of ephrins and Eph receptors in cancer. Cytokine Growth Factor Rev 15: 419-433, 2004.

3 Kullander K and Klein R: Mechanisms and functions of Eph and ephrin signalling. Nat Rev Mol Cell Biol 3: 475-486, 2002.

4 Pasquale EB: Eph receptors and ephrins in cancer: bidirectional signalling and beyond. Nat Rev Cancer 10: 165-180, 2010.

5 Miyazaki K, Inokuchi M, Takagi Y, Kato K, Kojima K and Sugihara K: EphA4 is a prognostic factor in gastric cancer. BMC Clin Pathol 13: 19, 2013.

6 Nakagawa M, Inokuchi M, Takagi Y, Kato K, Sugita H, Otsuki $\mathrm{S}$, Kojima $\mathrm{K}$, Uetake $\mathrm{H}$ and Sugihara K: Erythropoietinproducing hepatocellular A1 is an independent prognostic factor for gastric cancer. Ann Surg Oncol 22: 2329-2335, 2015.

7 Nasri B, Inokuchi M, Ishikawa T, Uetake H, Takagi Y, Otsuki S, Kojima K and Kawano T: High expression of EphA3 (erythropoietin-producing hepatocellular A3) in gastric cancer is associated with metastasis and poor survival. BMC Clin Pathol 17: 8, 2017 .
8 Szász AM, Lánczky A, Nagy Á, Förster S, Hark K, Green JE, Boussioutas A, Busuttil R, Szabó A and Győrffy B: Crossvalidation of survival associated biomarkers in gastric cancer using transcriptomic data of 1,065 patients. Oncotarget 7: 4932249333, 2016.

9 Japanese Gastric Cancer Association: Japanese classification of gastric carcinoma: 3rd English edition. Gastric Cancer 14: 101112, 2011.

10 Oki M, Yamamoto H, Taniguchi H, Adachi Y, Imai K and Shinomura Y: Overexpression of the receptor tyrosine kinase EphA4 in human gastric cancers. World J Gastroenterol 14: 5650-5656, 2008.

11 Lin CY, Lee YE, Tian YF, Sun DP, Sheu MJ, Lin CY, Li CF, Lee SW, Lin LC, Chang IW, Wang CT and He HL: High expression of EphA4 predicted lesser degree of tumor regression after neoadjuvant chemoradiotherapy in rectal cancer. J Cancer 8 : 1089-1096, 2017.

12 Oshima T, Akaike M, Yoshihara K, Shiozawa M, Yamamoto N, Sato T, Akihito N, Nagano Y, Fujii S, Kunisaki C, Wada N, Rino Y, Tanaka K, Masuda M and Imada T: Overexpression of EphA4 gene and reduced expression of EphB2 gene correlates with liver metastasis in colorectal cancer. Int J Oncol 33: 573-577, 2008.

13 Wang J, Dong Y, Wang X, Ma H, Sheng Z, Li G, Lu G, Sugimura $\mathrm{H}$ and Zhou $\mathrm{X}$ : Expression of EphA1 in gastric carcinomas is associated with metastasis and survival. Oncol Rep 24: 1577-1584, 2010.

14 Cui Y, Wu BO, Flamini V, Evans BAJ, Zhou D and Jiang WG: Knockdown of EPHA1 using CRISPR/CAS9 suppresses aggressive properties of ovarian cancer Cells. Anticancer Res 37: 4415-4424, 2017.

15 Wang Y, Yu H, Shan Y, Tao C, Wu F, Yu Z, Guo P, Huang J, Li J, Zhu Q, Yu F, Song Q, Shi H, Zhou M and Chen G: EphA1 activation promotes the homing of endothelial progenitor cells to hepatocellular carcinoma for tumor neovascularization through the SDF-1/CXCR4 signaling pathway. J Exp Clin Cancer Res 35: 65, 2016.

16 Dong Y, Wang J, Sheng Z, Li G, Ma H, Wang X, Zhang R, Lu G, Hu Q, Sugimura H and Zhou X: Down-regulation of EphA1 in colorectal carcinomas correlates with invasion and metastasis. Mod Pathol 22: 151-610, 2009.

17 Hess AR, Seftor EA, Gruman LM, Kinch MS, Seftor RE and Hendrix MJ: VE-cadherin regulates EphA2 in aggressive melanoma cells through a novel signaling pathway: implications for vasculogenic mimicry. Cancer Biol Ther 5: 228-233, 2006.

18 Cheng N, Brantley DM, Liu H, Lin Q, Enriquez M, Gale N, Yancopoulos G, Cerretti DP, Daniel TO and Chen J: Blockade of EphA receptor tyrosine kinase activation inhibits vascular endothelial cell growth factor-induced angiogenesis. Mol Cancer Res 1: 2-11, 2002.

19 Kataoka H, Igarashi H, Kanamori M, Ihara M, Wang JD, Wang YJ, Li ZY, Shimamura T, Kobayashi T, Maruyama K, Nakamura T, Arai H, Kajimura M, Hanai H, Tanaka M and Sugimura H: Correlation of EPHA2 overexpression with high microvessel count in human primary colorectal cancer. Cancer Sci 95: 13641, 2004.

20 Miao H, Gale NW, Guo H, Qian J, Petty A, Kaspar J, Murphy AJ, Valenzuela DM, Yancopoulos G, Hambardzumyan D, Lathia JD, Rich JN, Lee J and Wang B: EphA2 promotes infiltrative invasion of glioma stem cells in vivo through cross-talk with Akt and regulates stem cell properties. Oncogene 34: 558-567, 2015. 
21 Ishikawa M, Miyahara R, Sonobe M, Horiuchi M, Mennju T, Nakayama E, Kobayashi M, Kikuchi R, Kitamura J, Imamura N, Huang CL and Date H: Higher expression of EphA2 and ephrinA1 is related to favorable clinicopathological features in pathological stage I non-small cell lung carcinoma. Lung Cancer 76: 431-438, 2012.

22 Miao H, Li DQ, Mukherjee A, Guo H, Petty A, Cutter J, Basilion JP, Sedor J, Wu J, Danielpour D, Sloan AE, Cohen ML and Wang B: EphA2 mediates ligand-dependent inhibition and ligand-independent promotion of cell migration and invasion via a reciprocal regulatory loop with Akt. Cancer Cell 16: 9-20, 2009.

23 Chiari R, Hames G, Stroobant V, Texier C, Maillère B, Boon T and Coulie PG: Identification of a tumor-specific shared antigen derived from an Eph receptor and presented to CD4 T cells on HLA class II molecules. Cancer Res 60: 4855-4863, 2000.
$24 \mathrm{Xi} H Q$, Wu XS, Wei B and Chen L: Aberrant expression of EphA3 in gastric carcinoma: correlation with tumor angiogenesis and survival. J Gastroenterol 47: 785-794, 2012.

25 Lu CY, Yang ZX, Zhou L, Huang ZZ, Zhang HT, Li J, Tao KS and Xie BZ: High levels of EphA3 expression are associated with high invasive capacity and poor overall survival in hepatocellular carcinoma. Oncol Rep 30: 2179-2186, 2013.

$26 \mathrm{Xi} \mathrm{HQ}$ and Zhao P: Clinicopathological significance and prognostic value of EphA3 and CD133 expression in colorectal carcinoma. Clin Pathol 64: 498-503, 2011.

Received December 17, 2017

Revised January 12, 2018

Accepted January 15, 2018 